
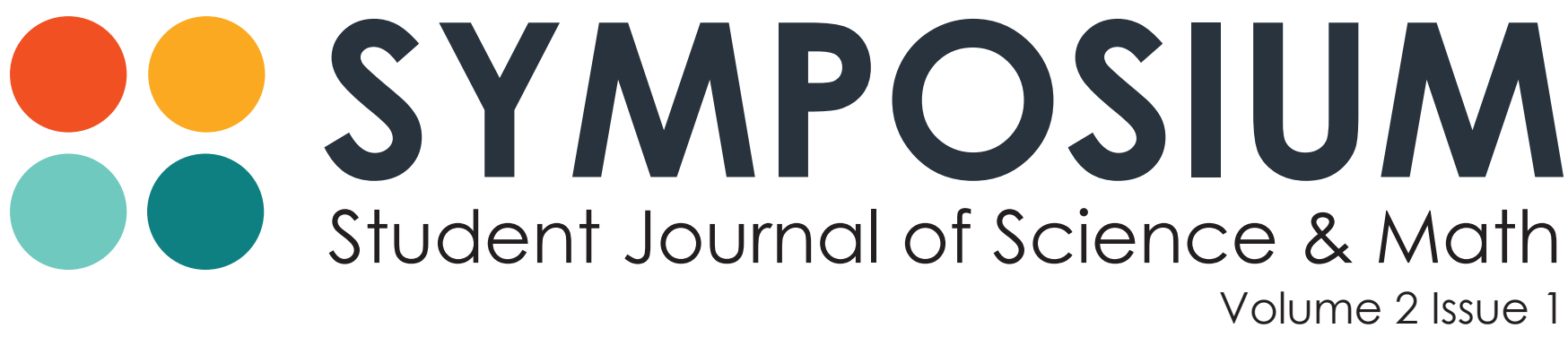


\title{
SIZE AND ABUNDANCE OF PISMO CLAMS IN THE INTERTIDAL AND SUBTIDAL
}

\author{
A RESEARCH ARTICLE \\ by Jenny Greene
}

\section{Introduction}

The Pismo clam, Tivela stultorum, was once the foundation of a thriving commercial and recreational fishery in California (Bureau of Marine Fisheries, 1949). While there has been concern and interest in monitoring and management of the Pismo clam population, little is known about the biology and distribution of the clams themselves. For example, the characterization of the abundance and distribution of clams across a depth gradient is unknown. Furthermore, the anthropogenic impact on the distribution of Pismo clams at a particular site through recreational fishing has also never been described.

The distribution of Pismo clams has been historically limited to sandy beaches from Monterey, California down to Baja, Mexico (Shaw \& Hassler, 1989). These clams exist primarily in the intertidal and shallow subtidal but have been observed in depths up to 80 feet (Weymouth, 1923). Pismo clams exhibit continuous growth, with age estimated by growth rings on the shell (Coe \& Fitch, 1950). These clams can grow approximately $20 \mathrm{~mm}$ in length per year for their first four years, with growth slowing after this period (Shaw \& Hassler, 1989). Pismo clams can grow to about II4mm (the minimum legal size limit for recreational fishing south of Monterey County) in 5 to 8 years (Shaw \& Hassler, 1989). Pismo clams possess sturdy, thick valves and a strong foot, which are favorable adaptations to this highenergy environment (Coe, 1947). Settling approximately one foot or less below the sand's surface, the clams extend their short incurrent and excurrent siphons just above the sand, filtering out small food particles (Coe, 1947). Clams tend to orient themselves with their incurrent siphon facing towards the shore to filter organic matter from the surf as it rushes back out to sea (Weymouth, I923). The high water turnover in the surf zone may provide favorable conditions for optimal nutrient circulation and availability (Knox, 2000).

Because Pismo clams inhabit the easily-accessible intertidal region (intertidal) and shallow subtidal 
region (subtidal), they are susceptible to human harvesting, which has altered the overall abundance of the species. Pismo clams have been harvested commercially and recreationally in California since the early I900s (Bureau of Marine Fisheries, 1949). The commercial fisher's most common method of clam collection was running a plow parallel to the low tide line, exposing the clams to the fishers (Weymouth, 1923). The Pismo clam commercial fishery was ranked third in economic importance of all mollusks due to high rates of human consumption and the importance of clam meat to the lucrative canning industry (Bureau of Marine Fisheries, 1949). Between 1916 and 1947, commercial diggers brought in an estimated total of 6.25 million pounds of clams, with an average annual catch of nearly I00,000 pounds (Bureau of Marine Fisheries, 1949). These catch rates could not be sustained, and the commercial fishery collapsed and closed in California in 1948 (Shaw et al., 1989). Pismo clams continued to be harvested commercially in Mexico and sold in the United States until at least 1965, after which clam imports to the U.S. were not identified by species (Pattison, 200I).

While the commercial fishery in California closed in 1948, recreational harvest of Pismo clams has continued into the present. Since the closure of the commercial Pismo clam fishery, recreational fishery has been suggested to be one of the largest contributing factors to Pismo clam population declines (Pattison, 200I). In November of 1949, Pismo Beach received an estimated 5,000 clammers per day (Pattison \& Lampson, 2007). Moreover, in 2.5 months in 1949 alone, recreational clammers harvested approximately 2 million clams (Pattison \& Lampson, 2007). The most common historical take sites of California, including Pismo Beach, have fewer numbers than in the peak days of clamming, with the scarcity of legal-sized individuals being most concerning to recreational clammers (Shaw \& Hassler, 1989).

In addition to decreasing overall clam abundance, heavy recreational fishing pressure could also alter the distribution of clams within a beach site. Accurate statistics for the number of current participants in the recreational fishery do not exist, but it could be in the several thousands (Pattison \& Lampson, 2007). There are limits to the recreational fishery that keep fishers from heavily depleting populations, though. As of 1986, the minimum legal size limit for take south of the Monterey and San Luis Obispo county boundary is II $4 \mathrm{~mm}$ ( 4.5 inches) and $125 \mathrm{~mm}$ ( 5 inches) north of that boundary (California Code of Regulations, 2005). Only io clams may be taken per person per day, and uncovered sublegal clams must be reburied (California Code of Regulations, 2005).

Participants in the recreational fishery can access clams in the intertidal on foot and in the subtidal by SCUBA or snorkeling. Diggers on foot comb beaches down to the low tide mark, probing the sand with a six-tined potato fork for the hard-shelled bivalves. The best time for them to harvest is when the tide is lowest, which provides the largest area of exposed beach. This lowest low tide mark - the division between the intertidal and subtidal — is a good approximation for limit of impact by clammers accessing Pismo clams from land (Davidson-Arnott \& Greenwood, 1999). Wave action around the low tide mark could deter diggers from searching the area, unless they choose to wade into the breaking waves and wash water. While wave action could deter clammers on foot, some people dive to access subtidal clams. Recreational SCUBA and free divers who participate in the recreational Pismo clam fishery commonly focus their digging efforts just beyond the breakers in the shallow subtidal but can be discouraged by heavy ocean swell and poor visibility (Rossier). The proportion of diggers on foot to divers is unknown, but there are likely far more clammers who access clams on foot, as accessing 
them subtidally requires more specialized equipment and skills.

Along with human impact, the resurgence of the southern sea otter, Enhydra lutris, has also been linked to declines of clam populations (Miller, 1977). When the otters re-populated the Pismo Beach region around 1978 , the recreational fishery saw a sharp decline from approximately 350,000 legal sized individuals collected in 1978 to zero in 1983 (McLachlan et al., 1996). From 1990 to 1992, there was a revival of legal-sized clams at Pismo Beach due to sea otter populations moving offshore to forage (McLachlan et al., 1996). When the otters returned in 1992, the fishery again saw a drop in recreationally-collected clam numbers, until 1993 when the last legal individual was found (McLachlan et al., 1996). Invertebrates make up approximately $75 \%$ of a sea otters diet, and feeding on all but very small clams, a sea otter can consume up to 24 clams in just 2.5 hours and approximately 80 clams per day (Feinholz, 1998; Stephenson, 1977). At this rate of foraging, increasing populations of sea otters could have devastating effects on Pismo clam numbers (Miller, 1977). Otter population numbers are on the rise north of Santa Barbara, but none have been observed south of Coal Oil Point (Tinker et al., 2008).

Surveys of beaches without otters and with a high population of Pismo clams could elucidate the impact of recreational fishing on the local distribution of Pismo clams. Rincon Beach provides the ideal study site to examine this impact for the following reasons: I) there are currently no otters at Rincon Beach (Tinker et al., 2008); 2) it receives pressure from clammers both by land and via SCUBA; and 3 ) it has an abundant population of Pismo clams. Preliminary data (personal communication Dan Averbuj) indicates that Rincon Beach may even have a higher abundance of clams than the surrounding areas also free from sea otter predation. Moreover, in 2013, the California Department of Fish and Wildlife (CDFW) found 735 clams (IO.I clams/m2) ranging from II to I24mm (Evans \& van Meeuwen, 20I3). While only one of these clams was legal-sized, Evans and van Meuwen also stated, "Given the rate of growth of Pismo clams, we expect that the population of legal-sized clams will dramatically increase at Rincon Beach two or more years from now barring poaching activities and environmental factors." Therefore, we used Rincon Beach as our study site to examine size and abundance patterns along a depth gradient from the intertidal, where clammers have access on foot, to the subtidal, where clammers would only have access with more specialized snorkeling or SCUBA equipment. We asked if I) clam abundance increases with distance from the shore and 2) clam size also increases with limited human access. We hypothesized that the clam populations at Rincon Beach would show higher abundance in the subtidal where humans have limited access from land. Moreover, we also hypothesized that legal-sized clams (greater than II4mm) would be more abundant in the subtidal. 


\section{Methods and Materials}

\section{Study Site}

Surveys were conducted at Rincon Beach (34.37820 N, -II9.48250 W) in Santa Barbara County, California. To understand the distribution of Pismo clams from the intertidal to the subtidal, we conducted two separate surveys: one in the intertidal on foot and one in the subtidal using SCUBA.

\section{Beach Surveys}

A team led by Cal Poly student Dan Averbuj and faculty member Dr. Benjamin Ruttenberg conducted beach surveys on foot at Rincon Beach on February I6, 20I5. Surveys were conducted between I2:00pm and 2:30pm with the low tide (-I.2 feet mean lower low water [MLLW]) at 2:05pm. Samplers surveyed four transects perpendicular to the water line. Each transect began up on the beach at a location determined at random by the samplers and extended as far toward sea as the wave action permitted (see transect locations listed in Table I). Transect sample areas were composed of repeating segments made of two PVC pipes connected by 3 meters of rope. Samplers surveyed one segment at a time by sticking the start end of the PVC pipe into the sand and stretching the rope toward the water line. Once an entire segment was sampled, the PVC pipe closest to the beach was taken out of the sand and rotated around the pipe closer to the water to extend a new segment of the transect toward the water. Sampling consisted of digging a trench in the sand with a 44-inch-long wood handle transfer shovel along the transect segment rope. The sampling area was approximately Io inches wide (the width of the shovel) and approximately I foot deep. The sampler would dig along the transect toward the water and, with the help of an observer, sift through the unearthed sand for clams and search for clams struck by the shovel. Samplers recorded the clam length in millimeters and the transect (I-4) in which the clam was found. The 3-meter segment within the transect was also recorded; however, the exact distance from shore for each clam location was not recorded. Therefore, the resolution of clam location for the intertidal surveys was 3 meters. The team sampled four total transects (Table I).

\section{Transect Mapping}

To extend the beach transects into the subtidal, we first generated the coordinates of the beach transects and plotted the desired coordinates for our diving transects. We used mapping software (ArcMap IO.2) to plot the locations of the beach transects using start and end coordinates recorded during beach sampling (Table I). Transect lines for the SCUBA surveys were drawn starting at the end (most seaward) point of each beach transect and extending away from the shoreline approximately Ioo meters, though the sampling distance of some transects was slightly shorter (Fig. I and Table I). A transect line laid parallel to shore was a guiWde for the location of the four perpendicular transects (Fig. 2). Prior to the subtidal surveys, the start coordinates and heading of this transect were determined, as well as the anchor point (meter mark) for each of the four transects. The anchor point of transect $\mathrm{I}$-indicated on Figure I with a star-was recorded and used as the starting point of the diving survey.

\section{Diving Surveys}

Diving surveys were conducted on a sandy bottom stretch of beach at Rincon Beach on March 6, 20I5. Surveys were conducted between 9:30am and I2:00pm with high tide $(+4.92$ feet MLLW) at 
9:36am. A team of four divers accessed the dive site by Zodiac from offshore. The predetermined start location of transect I, generated through the mapping software, was located with a hand held GPS unit (Garmin GPSMAP78) and marked with a dive flag (Fig. I). Divers descended and laid out a 50-meter transect tape, parallel to shore, held in the sand using Trident ${ }^{\bullet}$ screw-in sand anchors at either end of the transect (Fig. 2). At points along the parallel tape—set the same distances apart as the end points of the beach transects - four transects were laid out perpendicular to the parallel tape to line up and connect with previously sampled beach transects, as determined with the mapping software (Fig. I and Table I). For each of the four transects, surveys were conducted both landward and seaward from the parallel transect. All landward transects were surveyed as close to the high tide line as possible to maximize the landward survey area. With four divers, two transects could be surveyed simultaneously. Two divers swam along the perpendicular transect tape, sampling an area approximately io inches out from the transect tape to remain consistent with the intertidal sample area. Each sampler dragged a Fiskars ${ }^{\oplus}$ cultivator gardening fork tool (Fig. 3) in the sand across the sampling area, feeling the tines strike solid objects. Each fork had three tines approximately $23 \mathrm{~mm}$ apart. If they struck something, the divers would investigate by digging farther in the sand to see if it was a clam. If a clam was found, the sampler would record the clam's length and width to the closest millimeter (Fig. 4) and measure the water depth and the distance mark on the transect tape. They continued this process for all clams found along the 50-meter seaward segments and as far in the landward as possible while still being submerged.

\section{Data Analysis}

The data from the beach survey and diving survey transects were combined to create four continuous transects. As the beach transects did not all start at the same point up the beach, all distance measurements were adjusted to the o-meter mark of transect 2 (Table I "Beach Segment - Transect 2 Start Point" and Fig. I), as that was the point most landward. The distance from the starting point of transect 2 - the o-meter mark - to the starting point of all the other transects was found using mapping software. For each transect, this distance difference was added to the distance measures where clams were found so that all transects fell on the same distance scale.

For analysis, the four transects were split into two regions, intertidal and subtidal, based on the calculated distance of the lowest annual tide (Davidson-Arnott \& Greenwood, 1999) (Fig. 5). At Rincon Beach, this tide was -I.6 ft MLLW (Rincon Island, 20I4). To calculate the location of the lowest annual tide on our transects, we found the lowest point sampled in the beach sampling (-I.2 ft MLLW tide) and the highest point reached in the diving sampling (4.92 $\mathrm{ft}$ MLLW tide). Based on the difference in the tidal height between those two points (6.12 feet) and the distance between them ( 22 meters), we found that the beach sloped downward by approximately I foot with every 3.67 meters in lateral distance. We added I.47 meters to the -I.2 MLLW tide line to find the -I.6 tide line MLLWthe lowest annual tide at Rincon Beach in 20I4. Therefore, on our transects, the lowest low tide line fell at the 44.5 meter mark (Fig. 6).

\section{Relationship Between Clam Abundance and Distance From Shore}

The distances along the transects were binned into 3-meter segments-the smallest unit of measure used for intertidal sample segments. Clam abundance was summed per 3 meter bin. The effort of 
the diving sampling was double that of the beach sampling because divers dug on both sides of the transect; therefore, the abundance for each bin sampled during the diving surveys was divided by two. A Mann-Whitney nonparametric t-test was used to compare the abundance of clams in the intertidal versus the subtidal (JMP Pro II).

In addition, a model was fit to the data to estimate abundance versus distance from shore. A heuristic approach was taken to determine the factors included in the model. The first expression represented a Gaussian distribution (Wave Action Distribution) of clam abundance in the absence of predation-if clams potentially settled around the area of highest wave action (Fig. 9). We used the data point with the highest clam abundance to indicate the meter mark, perpendicular to shore, with the highest wave action $(\mathrm{Mw})$. Mw, coincidentally, was located at the MLLW tide mark. For the purposes of this analysis, we assumed Aw was represented by the highest abundance observed in our study and was found at Mw along the shore. The model (Wave Action and Predation Model)(Fig. 9) represents the combination of the Wave Action Distribution curve and the effects of predation. The second and third expressions represented the effects of predation in the intertidal and subtidal, respectively. It is likely that the consideration of more factors would yield a more accurate model, as this model was only based on the factors investigated in this study.

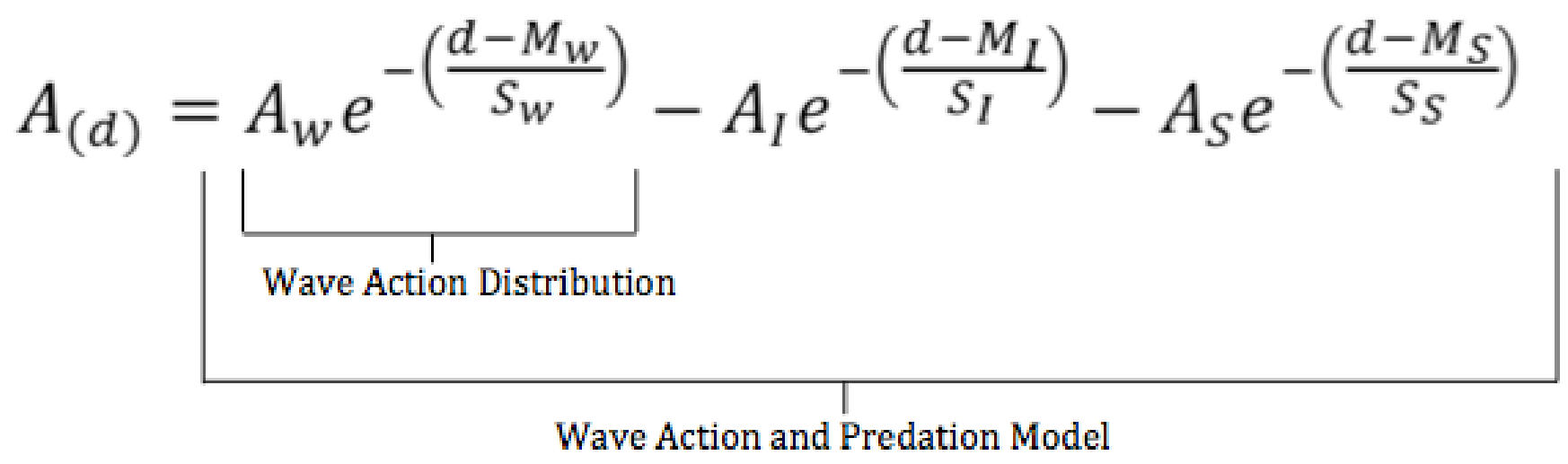

\begin{tabular}{|c|c|c|}
\hline Term & Description & Units \\
\hline$A_{(d)}$ & Spatial Density (Abundance) as a function of Distance from Shore & Clams $/ 3 \mathrm{~m}$ \\
\hline$A_{(w, I, S)}$ & Abundance Scale Factor & Clams $/ 3 \mathrm{~m}$ \\
\hline$d$ & Distance from Shore & $\mathrm{m}$ \\
\hline$M_{(w, I S)}$ & Peak Abundance Distance & $\mathrm{m}$ \\
\hline$S_{(w, I, S)}$ & Distance Dispersion Factor & $\mathrm{m}$ \\
\hline$w$ & Wave Action & - \\
\hline$I$ & Intertidal Predation & - \\
\hline$S$ & Subtidal Predation & - \\
\hline
\end{tabular}

\section{Relationship Between Length and Region}

All clams observed were used in these analyses, and data was not adjusted for effort. A one-way ANOVA test was done to analyze the differences between the mean length of clams found in the intertidal and subtidal regions (JMP Pro II). 
We tested whether human collecting had a greater impact on different size classes of clams in the intertidal or the subtidal. Clams were binned into five equal-sized classes: $0-28.5 \mathrm{~mm}$ (not used in the analysis as no clams fell into this range), $28.5-57 \mathrm{~mm}, 57-85.5 \mathrm{~mm}, 85.5-\mathrm{II} 4 \mathrm{~mm}$, and II4-I42.5mm. The size range of each class was determined by splitting II $4 \mathrm{~mm}$ - the legal clam size-equally five times, giving each class a $28.5 \mathrm{~mm}$ range. This smallest size bin is also the size of a clam slightly over one year old (Shaw \& Hassler, 1989). A Likelihood Ratio chi-square analysis was done to compare the ratio of the number of clams found in the intertidal and subtidal for each of the four size classes. Each group's ratio was compared to the others' to see if any ratios were significantly different (JMP Pro II).

\section{Results}

\section{Relationship Between Clam Abundance and Distance From Shore}

There was a significantly greater abundance of Pismo clams in the intertidal than the subtidal ( $\mathrm{p}<0.0018$, $\mathrm{DF}=\mathrm{I}$, Chi-Square=9.786) (Fig. 7). We found $\mathrm{I} 85$ clams in the intertidal and 66 in the subtidal. There was a section of relatively high clam abundance from the 18 to 40 -meter marks with peaks at both ends of that range (Figs. 6 and 8). No clams were found beyond the 96-meter mark (Fig. 8).

We measured the relationship between distance from shore and abundance due to wave action, intertidal predation, and subtidal predation using a Gaussian model, and compared it to the actual data found $\left(\mathrm{SSE}=98 \mathrm{I} .8 \mathrm{I}, \mathrm{R}^{2}=0.630\right.$ ) (Fig. 9). The model gave a lower estimated curve of abundance than the observed data. The residuals of the actual abundance data distribution, and the model appeared to be normally distributed.

\section{Relationship Between Length and Region}

The one-way ANOVA showed that the mean length of clams in the intertidal region was $98.37 \mathrm{~mm}$ (Std. Dev. $=15.033, S E=1.0942$ ), and the mean length of clams in the subtidal region was $102.259 \mathrm{~mm}$ (Std. Dev.=15.159, SE=I.2606) (Fig. I0). These means were significantly different $(\mathrm{p}<0.0236, \mathrm{~F}=5.1749)$. The Likelihood Ratio analysis showed that at least one of the size class ratios of intertidal count to subtidal count was significantly different from the others (Chi-Square $=I 1.8 \mathrm{I} 5, \mathrm{DF}=3, \mathrm{p}<0.0080$ ). When all size class ratios were compared with one another, the II4-I42.5 $\mathrm{mm}$ size class ratio was found to be significantly different from the other classes (Chi-Square>5.I39, DF=I, $\mathrm{p}<0.0234$ ), as the subtidal had a higher proportion of legal clams than the intertidal (Fig. II). No other size classes were found to have significantly different ratios than the other size classes.

\section{Discussion}

We hypothesized that, due to the restricted access by humans, Pismo clam abundance at Rincon Beach would be higher, and clam size would be greater in the subtidal. Contrary to our hypothesis, we found that clams were less abundant in the subtidal than the intertidal (Fig. 7), but the overall size 
of clams was greater in the subtidal than the intertidal (Fig. Io). Moreover, the distribution of clams followed a Gaussian distribution with a peak of abundance in the zone with the most wave action and abundance tapering off away from this peak in both the landward and seaward directions (Fig. 6). There are several factors that may be influencing the patterns of distribution observed. Here, we explore the impact of recreational fishing, wave action, and predation by non-human predators on the abundance and distribution of Pismo clams.

Recreational fishing is known to alter the abundance and size distribution of several species of marine invertebrates (Griffiths et al., 2006; Cecilia et al., 2005; Alexander et al., 20I4). However, for the Pismo clam population at Rincon Beach, CA, recreational fishing appears to only affect the distribution of legal-sized clams, not overall abundance. If recreational fishing pressure had an impact to overall clam abundance, we would expect Pismo clams to be less abundant in the intertidal, where humans have greater access, than the subtidal, where human access is more limited. However, we saw the reverse trend, with higher overall clam abundance in the intertidal than the subtidal (Fig. 7), demonstrating that recreational fishing has no effect on the overall abundance distribution of clams, particularly of sub-legal clams, and that other factors must have significant influence.

While recreational fishing pressure did not affect the abundance of Pismo clams, it did affect the distribution of the largest size class of clams - those that were legal-sized and larger. This suggests that the impact of recreational fishing on clams was restricted to legal clams, and the impact of poaching sub-legal clams was negligible. More clamming effort in the intertidal is likely a causal factor in finding fewer legal individuals in the intertidal than the subtidal (Fig. II). While legal clams in the subtidal are also subject to recreational fishing pressure due to diving, diving for clams requires more specialized skills and equipment; therefore, the majority of participants in the recreational fishery are likely clammers on foot in the intertidal, not divers or snorkelers. The overall trends of increasing abundance and size with distance were also observed in the CDFW survey of Rincon Beach in 2013 (Evans \& van Meeuwen, 20I3); this suggests that these patterns have persisted at Rincon Beach. The subtidal, beyond the lowest low tide line, was not observed; however, they did find the same trend of increasing abundance up to that line, with the highest areas of abundance just landward of the low tide line. They only found one legal-sized clam, but it was found within the farthest seaward area of their sampling. Because the CDFW study only observed Pismo clams in the intertidal, we do not have a frame of comparison at this specific site for the trends that we found in the subtidal.

Recreational fishing also affects the size class distributions of other species. For example, recreational harvest has also affected the size class distribution of giant clams, Tridacna maxima. Larger individuals were found in higher abundance in areas of their subtidal habitat that were less accessible to humans (Bodoy, 1984). Another example of human impact on size distribution comes from the studies of the South American clam, Tivela mactroides. In the study area, clams of about $30 \mathrm{~mm}$ in length were targeted, and in areas with higher human access, there was a greater abundance of 20$25 \mathrm{~mm}$ individuals, just below the targeted size (Cecilia et al., 2005). A study that compared no-take reserves to areas where recreational harvesting is permitted found that clam digging had a substantial influence on decreasing the abundance of target species within legal take size ranges (Griffiths et al., 2006). In addition, Griffth et al. (2006) specifically studied sites in which confounding effects, like wave energy, were minimized to pinpoint anthropogenic effects. 
While there was an impact of fishing pressure on large clams, smaller size classes (28.5-II3.9 mm) were not affected by human access (Fig. II). Our data cannot address the impact of human access on clams smaller than $28.5 \mathrm{~mm}$ as we did not find any in our intertidal or subtidal sampling. However, it is probable that very small individuals — shorter in length than the smallest clam found ( $42 \mathrm{~mm})$-were present in the sampling area but difficult to account for. In the beach surveys, they could have been overlooked by samplers; in the diving surveys, clams smaller than the gaps between the sampling tool tines $(<23 \mathrm{~mm})$ could have slipped through the tines or were not felt when struck. While it is unlikely that these small sizes are being fished, human access could still be affecting small clams through trampling or other activities (Moffet et al., I998,). Moffet et al. (1998) found that trampling had a significant impact of decreasing the abundance of small surf clams (Donax serra) because the clams tend to settle closer to the surface and have thinner, more fragile shells.

While recreational fishing pressure has a strong influence on the distribution of legal-sized clams at Rincon Beach, wave action may be responsible for the overall patterns of abundance distribution for the population as a whole (Fig. 6). The area in which most clams seemed to cluster correlated with the swash zone: the area with the most wave action, and thus, the highest nutrient churning and availability (Knox 2000). Examples from other organisms demonstrate that the swash zone has peaks of abundance for other species as well. A similar study of the spatial distribution of Tivela mactroides found the same trends of high clam abundance in the surf zone just above the lowest low tide mark (Cecilia et al., 2005)(Fig. 3). Other species of clams (Donax hanleyanus, Mya arenaria) also preferentially settle in the swash zone, with increasing abundance patterns up the lowest low tide mark and a decrease into he subtidal, similar to our data (Matthiessen, 1960; Cardoso \& Veloso, 2003). These clam species also display differences in their size distribution, with smaller individuals settling farther shoreward and larger individuals farther seaward (Matthiessen, 1960; Cardoso \& Veloso, 2003).

Moreover, this pattern is not limited to clams or invertebrates. In a study on the effects of wave action on productivity and post-settlement patterns of intertidal organisms, Leigh et al. (1987) found that sea palms, Postelsia palmaeformis, only settle in areas of high wave action; and mussels, Mytilus californianus, preferentially settle in the high surge of the low rocky intertidal, similar to the observed Pismo clam distribution. This high-energy environment provides a constant overturning of nutrient-filled water, allowing for optimum rates of productivity (Leigh et al., 1987). Talbot et al. (1990) describes high numbers of phytoplankton cells in the surf zone relative to the areas beyond the surf zone, indicating that wave action delivers high quantities of nutrients to organisms in these high wave energy environments. Therefore, clams may preferentially group in these areas to access the more abundant food sources. Further support for this idea comes from the fact that Pismo clams orient themselves with their incurrent siphon facing towards the shore (Weymouth, I923). Wash water and waves returning to sea can deliver large quantities of phytoplankton for the clams to filter (Talbot et al., 1990).

We found an area of low abundance just beyond the low tide mark at 44.5 meters (Fig. 6), which can be explained by several factors. There could be a zone of less wave action in this area that clams may avoid; if this area experiences, on average, less wave action and less nutrient availability, clams may preferentially settle a small distance away in an area of higher nutrient turnover. Another possible reason for this gap in abundance could be the patchy distribution of Pismo clams (Stephenson, 1974). Stephenson (1974) found that, within some beaches of Monterey, clams followed patchy distributions, 
and many were found buried right next to each other-a pattern that we also observed in our sampling. Therefore, the decreased abundance around the 44.5-meter mark could also be a break between patches of clams. These patches in the subtidal tended to correspond to areas in which sediment was larger in grain size, less tightly packed, and arranged into small mounds, as opposed to stretches of flat, tightly packed sand in which relatively few clams were found (personal observation). Studies of sandy beach macrofauna discovered a positive relationship between increasing sand grain size and greater species richness and abundance (Defeo \& McLachlin, 2005).

Animal predation could be influencing the patterns of abundance and distribution as well. Sea otters have been shown to affect overall abundance at a beach site (Miller, 1975). However, sea otters are likely not influencing current Pismo clam distributions at Rincon Beach, CA, as they have not been observed in the area south of Coal Oil Point since the early I90os (Lafferty \& Tinker, 20I4). Other subtidal predators of the Pismo clam include moon snails (Polinices spp.), bat rays (Myliobatis californica), and rock crabs (Cancer spp.) (Pattison \& Lampson, 2007). If predators do affect the system, they could contribute to the patterns of lower abundance subtidally. While humans limit legal-sized clams in the surf zone, subtidal predators, like the Pacific sea star (Pisaster ochraceos), limit the seaward expansion of mussels to the edge of the surf zone, as sea stars avoid areas of heavy wave surge (Leigh et al., 1987). The smaller subtidal predators of the Pismo clam, like the moon snail and various crab species, may prefer smaller individuals due to a thinner shell (Coe, 1947) and therefore, would have a greater influence on the size distribution of smaller clams in the subtidal.

The model of the abundance data provides a proof of concept that there are predictable factors that drive the abundance distribution of clams (Fig. 9). The data suggest that wave action, not fishing pressure, is responsible for the overall distribution of clams. Our model also supports this idea. If clams prefer areas of high wave action with no added biological or predation factors, the distribution should follow a normal Gaussian distribution with a peak at the lowest low tide mark, around which wave action is greatest. Our data appeared to follow this distribution but in lower abundance than expected if wave action were the only factor affecting clam distribution (See "Wave Action Distribution" in Fig. 9). With the added effects of human and other biological predation in the intertidal and subtidal, a curve was created that slightly underestimated the values of abundance relative to the data found. Based on the proposed model, it would appear that, if human fishing pressure were a significant factor in shaping clam abundance distribution, the overall observed abundance would be much lower. If the model was adjusted to only include the effects of wave action and animal predation, we might expect a curve more closely resembling the actual observed distribution. This reflects the idea that there are other factors, like biological predation, affecting the abundance distribution in the subtidal.

Our study indicates that wave action likely has the greatest effect on the abundance patterns of Pismo clams at Rincon Beach, CA and that recreational fishing pressure is a contributing factor to the distribution of legal-sized individuals. This study also marks the first attempt to assess the distribution of clams both in the intertidal and subtidal at a particular beach without sea otter predation. Furthermore, we can use our model to assess the various factors affecting Pismo clam abundance distribution. In the model, the area under the curve gives an estimate of clam density for a given area sampled. If similar data were collected at other beaches and showed a similar trend of clam abundance, then an estimate of the population for that entire beach could be found. For future use, this model could be modified 
to encompass many other factors that shape the abundance distribution of Pismo clams. While our model takes into account some of these factors and is useful for estimating clam abundance, a better understanding of the distribution at deeper depths is needed. Based on personal observation, clams settled even further out into the subtidal than we surveyed, as many siphons could be seen from the surface beyond the scope of the diving surveys. Therefore, extending the transects farther into deeper water could elucidate patterns of abundance and distribution of Pismo clams. Further observations of distribution in areas with certain sediment characteristics may also provide insight into clam settling habits. In addition, studies looking into the patchy distributions of clams could reveal more about the trends of aggregation of the size classes that were observed but not investigated in this study.

\section{Acknowledgements}

Thank you to my advisor, Dr. Lisa Needles, and to Grant Waltz for helping me create this research study, and for the many edits of this paper. I thank Dr. Ben Ruttenberg and Dan Averbuj for allowing me to use their beach sampling data, Dr. Gary Hughes for helping me create our clam abundance model and for all the stats advice. And thank you Connor Healy, Eric Anderson, and Grant Waltz for sticking with me through all the long diving days. 


\section{References}

Alexander, T., Johnson, C., Haddon, M., Barrett, N., \& Edgar, G. (20I4). Long-term trends in invertebrate-habitat relationships under protected and fished conditions. Marine Biology, I6I(8), I799-1808.

Bodoy, A. (1984). Assessment of human impact on giant clams (Tridacna maxima) near Jeddah, Saudi Arabia. Proc. Symp. Coral Reef Environ. Red Sea, Jeddah, Saudi Arabia, 472-490.

Bureau of Marine Fisheries (1949). The commercial fish catch of California for the year 1947 with a historical review 1916-1947. Calif. Fish Bull, 74, 267.

California Code of Regulation (2005). Title I4, Natural Resources. California Coastal Commission.

Cardoso, R., \& Veloso, V. (2003). Population dynamics and secondary production of the wedge clam Donax hanleyanus (bivalvia: Donacidae) on a high-energy, subtropical beach of brazil. Marine Biology, I42(I), I53-162.

Cecília Z. Amaral, A., Denadai, M., \& Turra, A. (2005). Along-and across-shore components of the spatial distribution of the clam tivela mactroides (born, 1778) (bivalvia, veneridae). Journal of Natural History, 39(36), 3275-3295.

Coe, W.R. (1947). Nutrition, growth and sexuality of the Pismo clam (Tivela stultorum). J Exp. Zool., IO4(I), I.

Coe, W.R. \& Fitch, J.E. (1950). Population studies, local growth rates and reproduction of the Pismo clam (Tivela stultorum). J. Mar. Res, 9(3), I88-210.

Davidson-Arnott, R.G.D., \& Greenwood, B. (1999). Waves and sediment transport in the Nearshore Zone. Encyclopedia of Life Support Systems, I-4.

Defeo, O., \& McLachlan, A. (2005). Patterns, processes and regulatory mechanisms in sandy beach macrofauna: A multi-scale analysis. Marine Ecology Progress Series, 295, I-20.

DFG Pismo Clam Survey Data (2009). May 2008-March 2009, Department of Fish and Wildlife, I-4.

Evans, K., \& van Meeuwen, T. (2013). Invertebrate Project: Intertidal Pismo Clam Survey. Calif Dep of Fish and Wildlife Field Report, I-9.

Griffiths, J., Dethier, M., Newsom, A., Byers, J., Meyer, J. (2006). Invertebrate community responses to recreational clam digging. Marine Biology, I49(6), I489-I497.

Knox, G.A. (2000). The ecology of the seashores, Boca Raton, Florida: CRC Press LLC. pp. 218.

Lafferty, K., \& Tinker, M. (20I4). Sea otters are recolonizing southern California in fits and starts. Ecosphere, $5(5)$.

Leigh, E.., Paine, R., Quinn, J., \& Suchanek, T. (1987). Wave energy and intertidal productivity. Proceedings of the National Academy of Sciences of the United States of America, 84(5), I3I4-I318.

Matthiessen, G. (1960). Intertidal zonation in populations of mya arenaria. Limnology and Oceanography, 5(4), 38I-388.

McLauchlin, A., Dugan, J.E., Defeo O., Ansell, A.D., Hubbard, D.M., Jarmille, E., Penchaszadeh, P.E. (1996). Beach Clam Fisheries. Oceanography and Marine Biology, 34, 163-232.

Miller, D.J. (1977). Status of the sea otter population in California and the potential management of otter and shellfish resources, Cal-Neva Wildlife Transactions, 44.

Moffett, M., McLachlan, A., Winter, P., \& De Ruyck, A. (1998). Impact of trampling on sandy beach macrofauna. Journal of Coastal Conservation, $4(\mathrm{I}), 87-90$.

Pattison, C. (200I). California's living marine resources: A status report, Pismo clam. California Department of Fish and Game. I35-I37

Pattison, C. (2006) revised Lampson, K. (2007). Annual Status of the Fisheries Report, Pismo clam. California Department of Fish and Game, 6, I-II.

Rincon Island, California Tide Chart, 20I4. Retrieved from http://tides.mobilegeographics.com/calendar/year/5334.html? $y=20 \mathrm{I} 4 \& \mathrm{~m}=4 \& \mathrm{~d}=\mathrm{I}$

Rossier, R.N. (n.d.). What is visibility? Illuminating facts about an unclear situation. Retrieved from http://www.dtmag.com/Stories/Dive\%20 Weather/II-95\%20weather\&waves.htm, Dive Training Magazine.

Shaw, W., \& Hassler J. (1989). Species profile: Life histories and environmental requirements of coastal fisheries and invertebrates (Pacific 
Southwest) - Pismo clam. U.S. Army Corps of Engineers Report, I-9.

Stephenson, M. (1974). Distribution and reproduction of the Pismo clam in Monterey Bay. California State University, Hayward, I-24.

Talbot, M.M.B., Bate, G.C., \& Campbell, E.E. (1990). A review of the ecology of surf zone diatoms, with specific reference to Anaulus ostralis. Oceanography and Marine Biology Annual Reviews, 28, I55-175.

Tinker, T., Hatfield, B., \& Maender, G. (2008). California sea otters: Population recovery continues at a slower rate. Sound Waves-US Geological Survey, 108, I-3.

Weymouth, F.W. (1923). The life history and growth of the Pismo clam (Tivela stultorum Mawe). California Fish and Game Commission, 9-Io. 


\section{Table Legend}

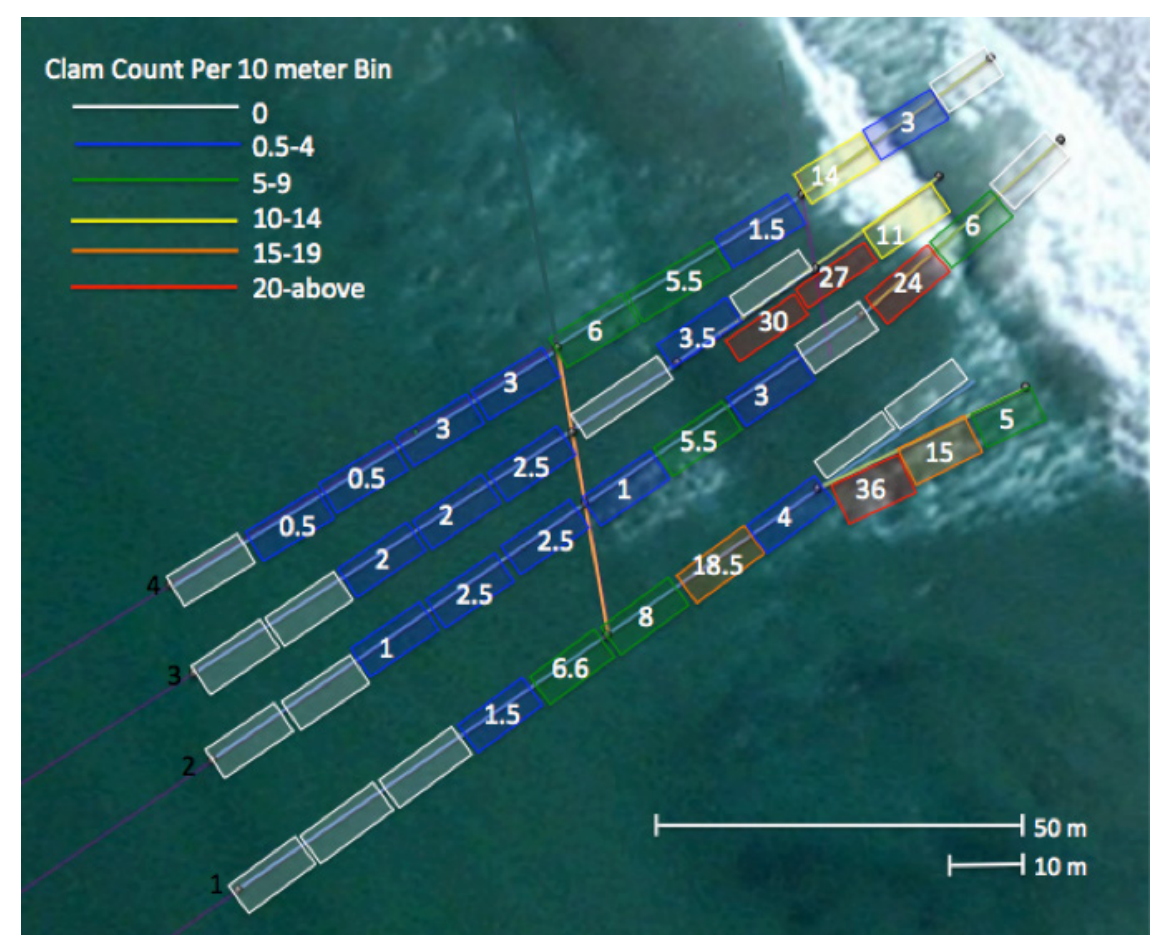

Table I. Intertidal and subtidal transect locations, coordinates, and lengths. Some transects have overlapping sampled areas between the intertidal and the onshore portion of the subtidal. See Fig. I for visual layout of transects. 


\section{Figure Legend}

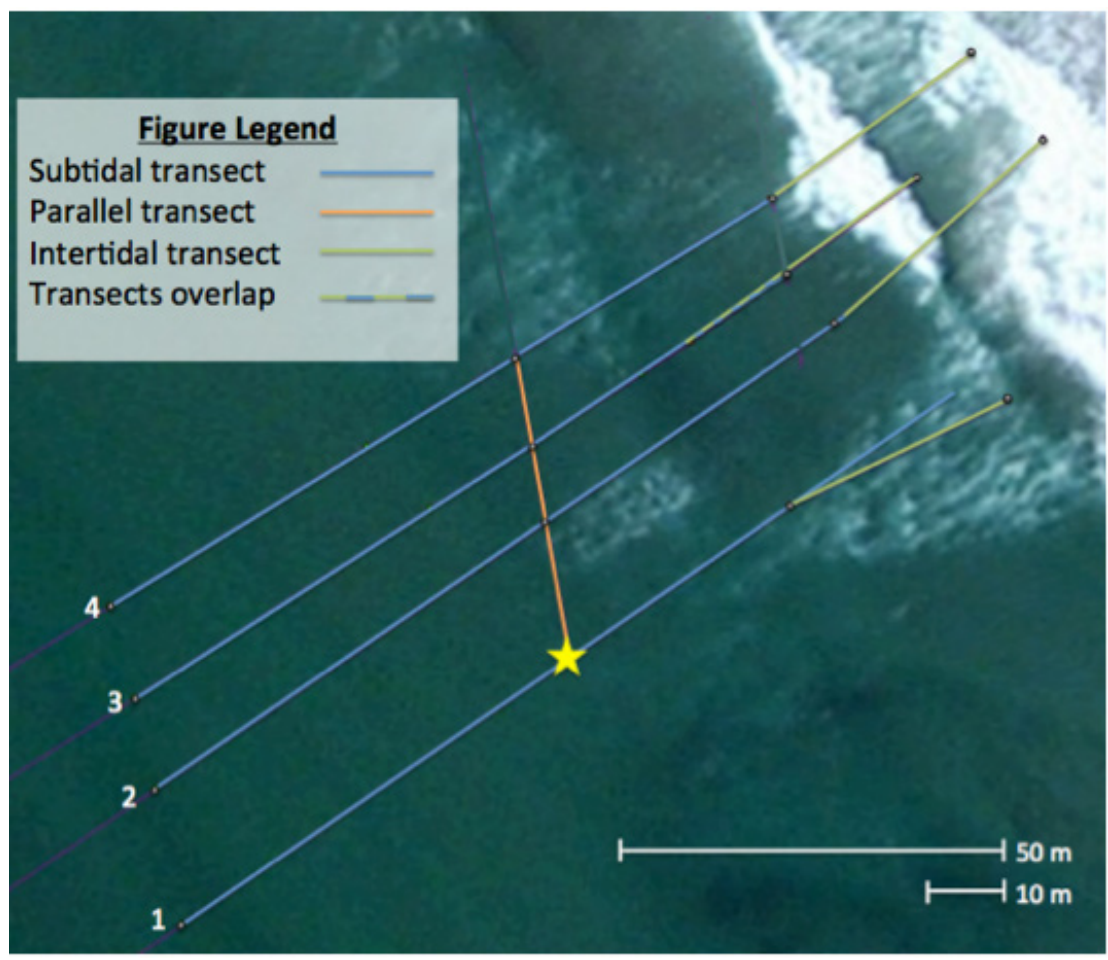

Figure I. Diving and beach survey transect layout at Rincon Beach, with transect numbers indicated. The midpoint of transect I was the original anchor point for the diving sampling (indicated with a star). Note: Background image taken at high tide. The water line was lower during the beach sampling. (Background image: Esri) 


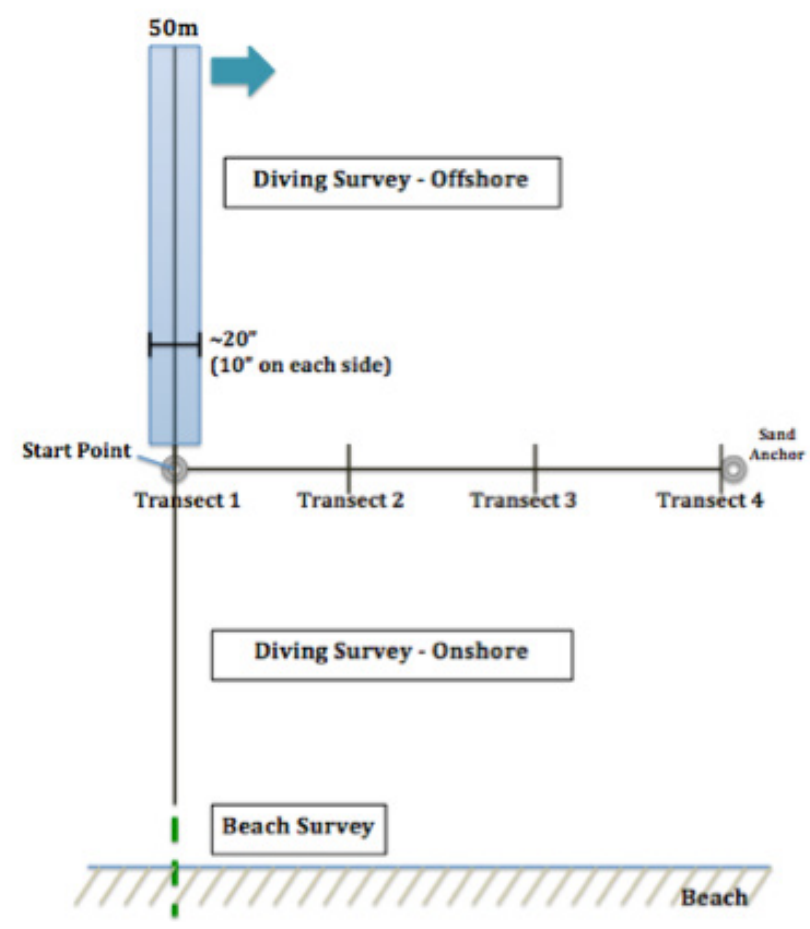

Figure 2. Diving survey layout. The transect between the sand anchors was laid parallel to the shore, and the perpendicular transects were sampled in both the onshore and offshore directions. The sampling area was approximately Io inches on both sides of the perpendicular transects and was uniform for all transect segments sampled. The blue arrow indicates that the same sampling area and methods carried over to all four transects. Diving transects connected to previously sampled beach transects (indicated by the green dashed line). Intertidal transects extended farther up onto the beach. 


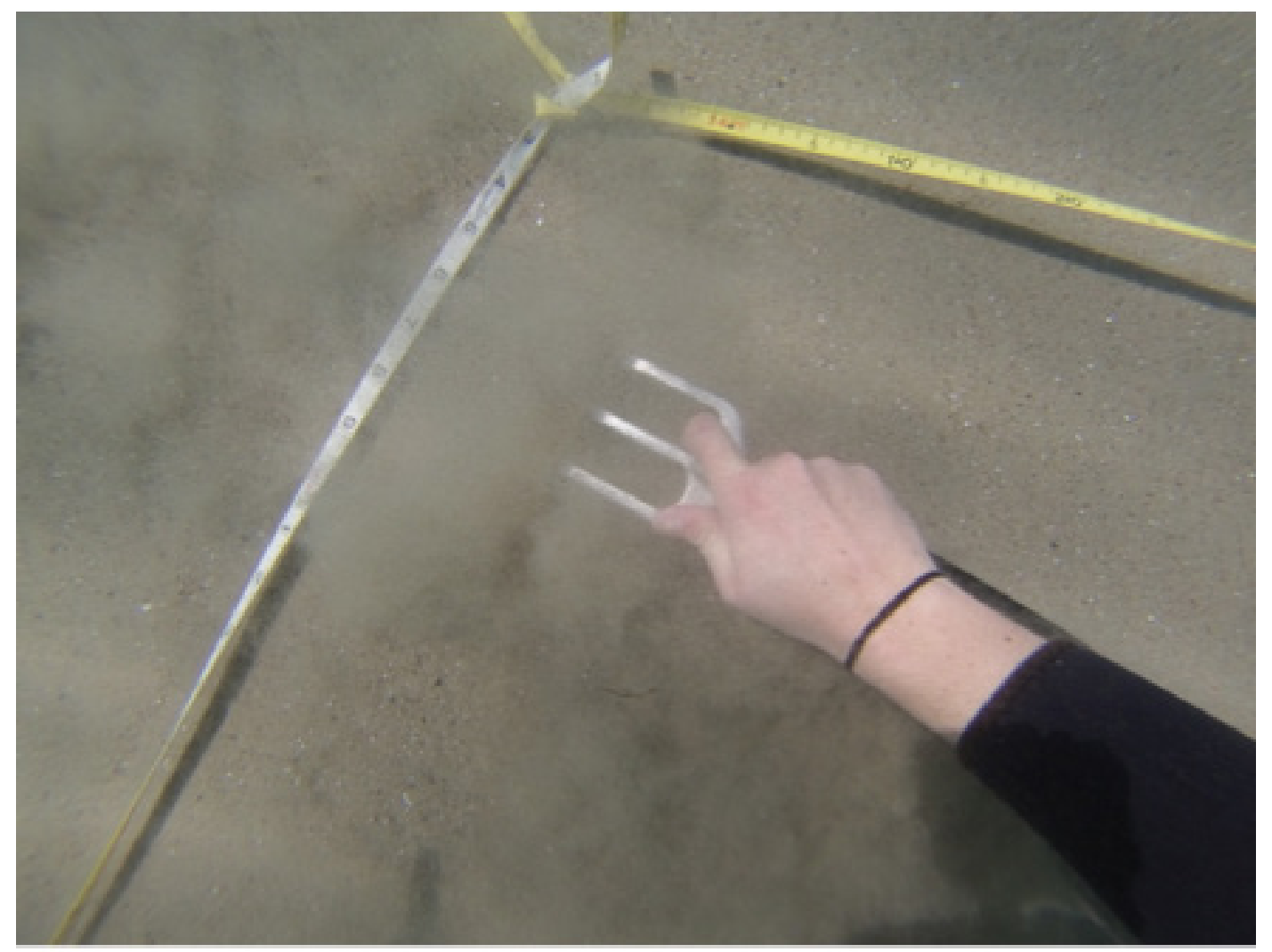

Figure 3. Diver using the Fiskars ${ }^{\circ}$ cultivator gardening fork tool within the sampling area to search for clams.

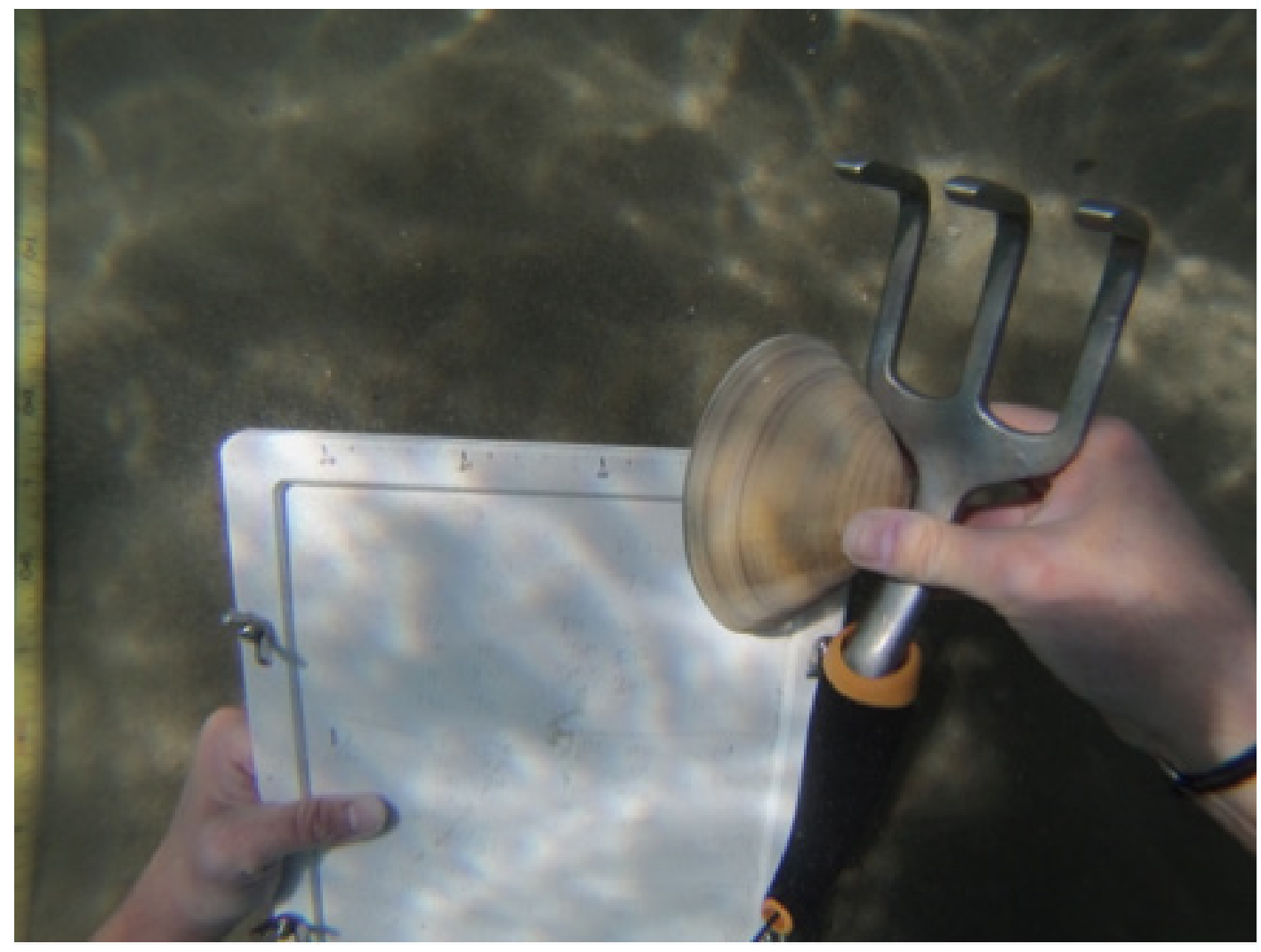

Figure 4. Clam width being measured and recorded. 


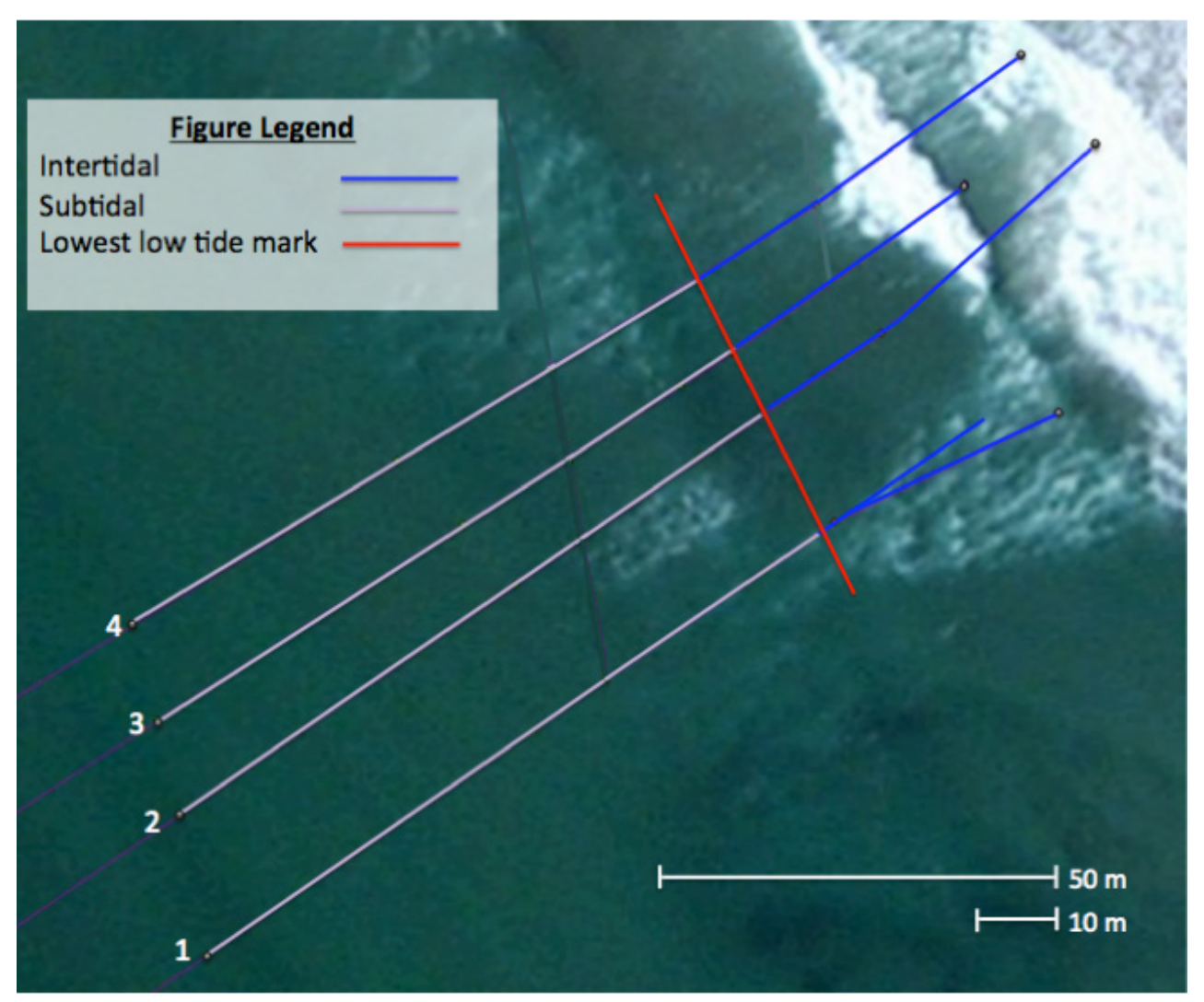

Figure 5. The separation of the intertidal and subtidal regions. The red line parallel to the beach represents the lowest low tide mark for Rincon Beach. The subtidal region composed of area sampled in the diving surveys. The intertidal region was a combination of area sampled during diving and beach surveys. Note: Background image taken at high tide. The water line was lower during the beach sampling. (Background image: Esri) 


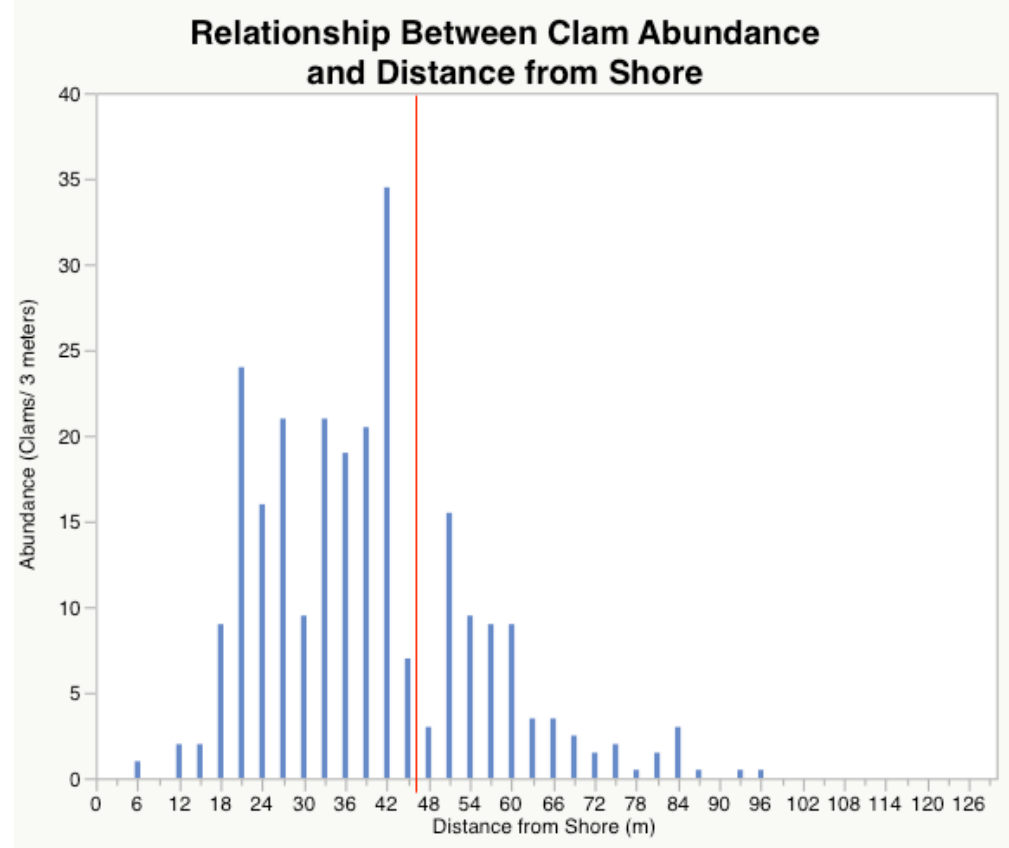

Figure 6. A histogram of clam abundance vs. distance from shore. Distances along transect were binned into 3-meter-long segments, and the abundance of clams within each bin was found. Bars represent the count of clams in each bin. The red line indicates the cut-off between intertidal and subtidal (44.5 $\mathrm{m}$ ), which corresponds to the lowest low tide line at Rincon Beach (see Fig. 5).

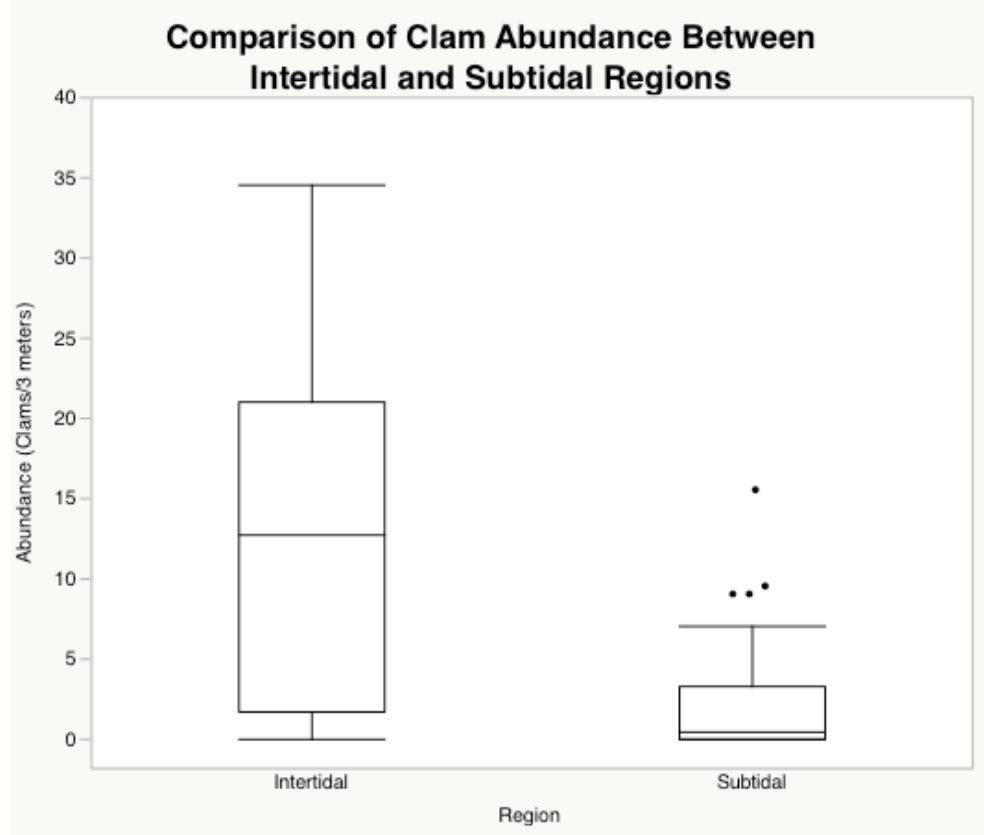

Figure 7. Comparison of clam abundance in the intertidal and subtidal. Clam abundance was significantly higher in the intertidal than in the subtidal ( $p>0.0018, D F=I$, Chi-Square=9.786). I85 clams were found in the intertidal and 66 in the subtidal. 


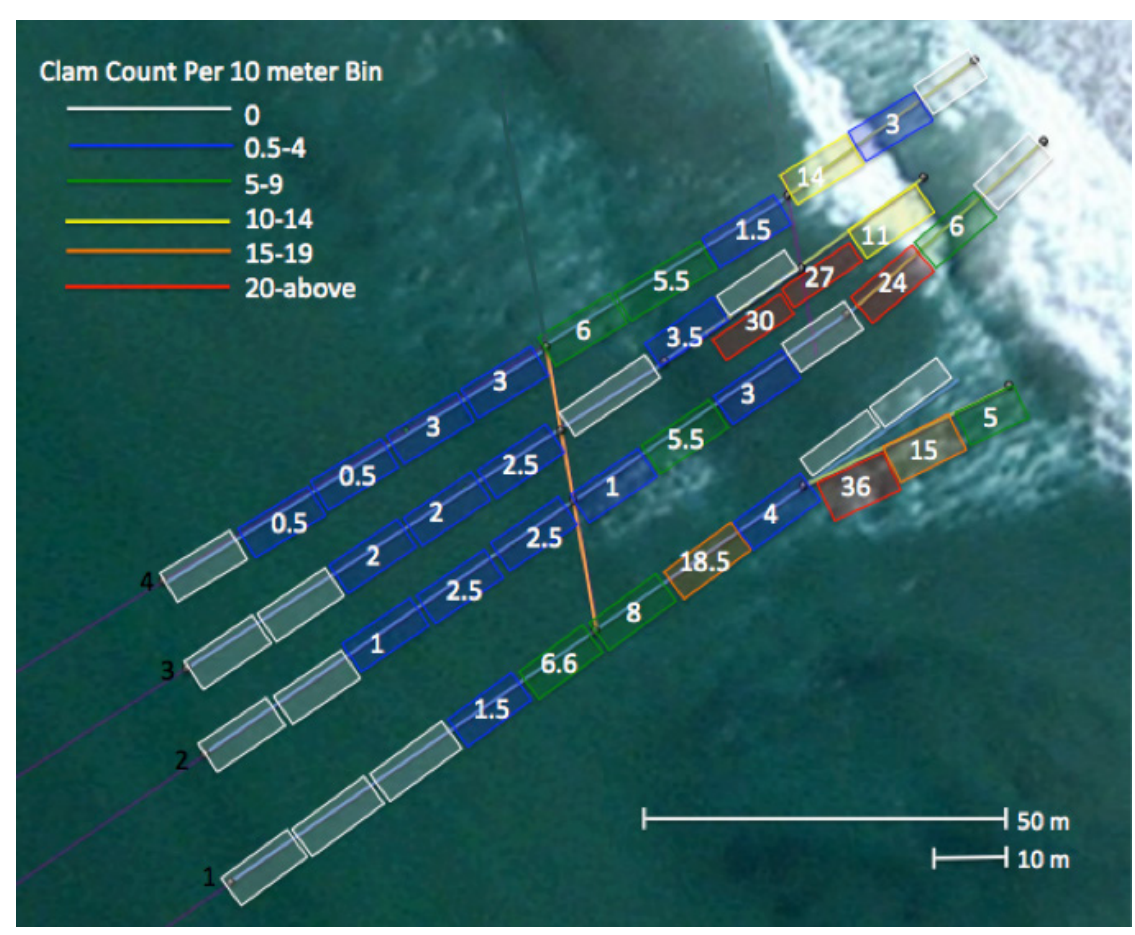

Figure 8. Clam abundance counts for both subtidal and intertidal samples. Transects were divided into Io-meter sections (Note: Does not correspond to abundance data represented graphically in which clams were grouped into 3-meter-long sections of the transects). All clams found within that section were added together, and the total number is found in the bin for that section. Figure 4 shows the separation of intertidal and subtidal transects. Subtidal counts were adjusted for effort (i.e. Effort in the subtidal was twice that of the intertidal, so subtidal counts were divided by two). Transects I and 3 had an overlap in sampling area between the intertidal and subtidal. For both transects, the boxes on the bottom of the transect line correspond to the intertidal counts. Note: Background image taken at high tide. The water line was lower during the beach sampling. (Background image: Esri). 


\section{Relationship Between Abundance and Distance, With Model}

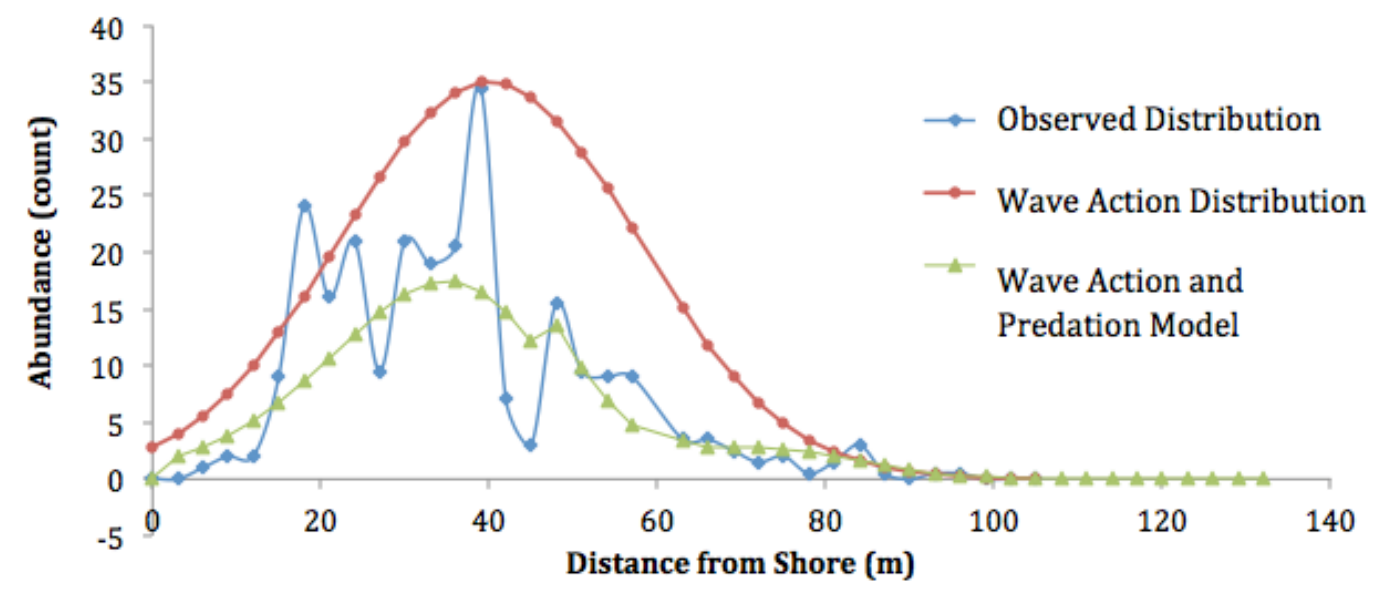

Figure 9. The scatterplot and trend line of the actual clam abundance vs. distance from shore data with the wave action and predation model (SSE $=981.81, R 2=0.630$ ). The distribution represented by the green line combines the effects of wave action and predation on distribution. The curve represented by the red line indicates a possible pattern of abundance in the absence of predation assuming preferential settlement around areas of high wave action. See Results section "Abundance Distribution Model" for the model function and parameters.

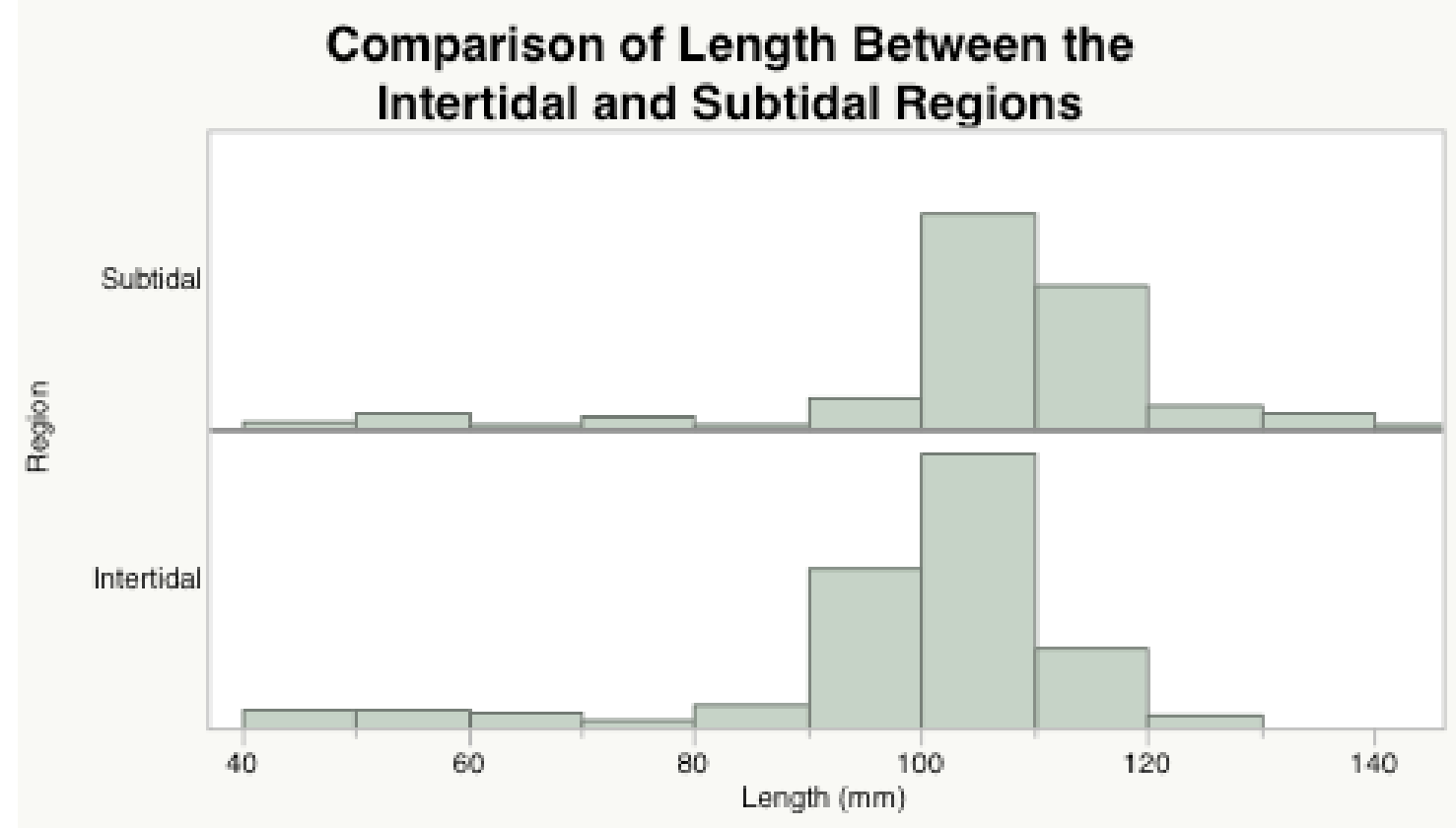

Figure Io. A histogram comparing the mean clam length in the intertidal and subtidal. The mean lengths of the regions were: intertidal $=98.367 \mathrm{~mm}$ and subtidal $=102.159 \mathrm{~mm}$. This data does not reflect an adjustment for double the sampling effort in the subtidal. 


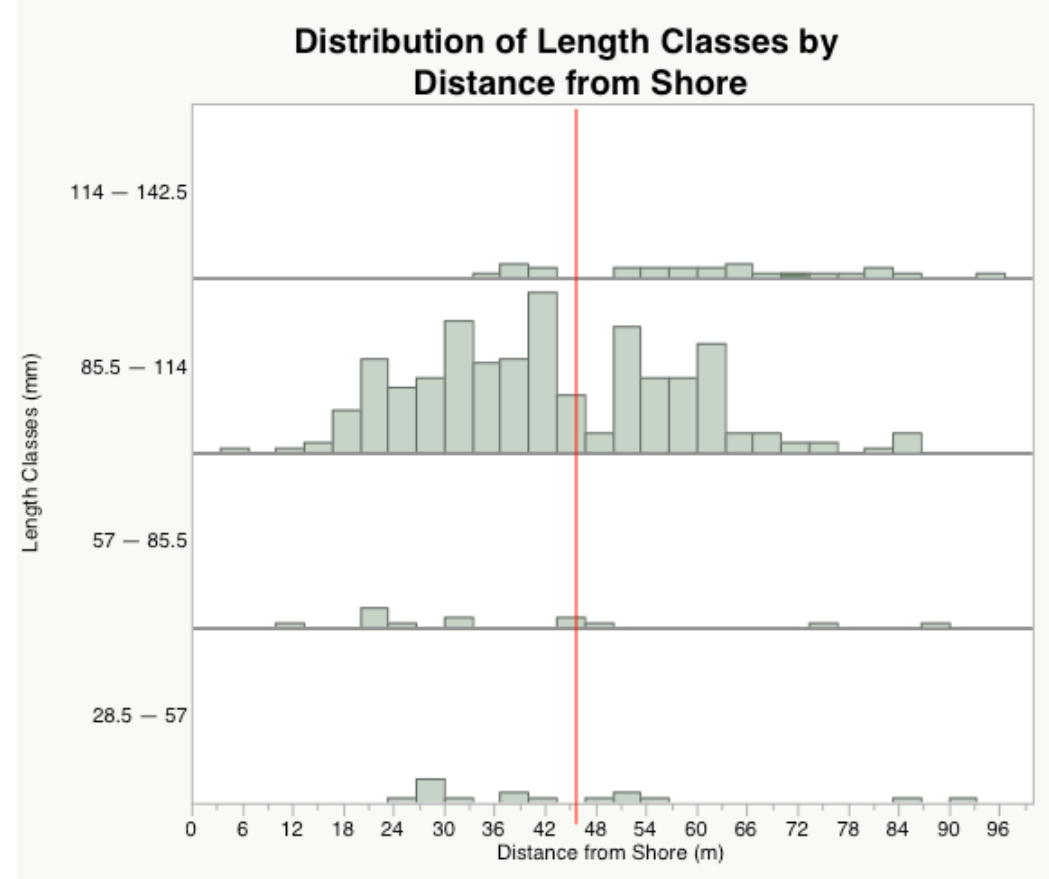

Figure II. Distribution of length classes in relation to distance from shore. The cut-off for legal-sized clams is II4 mm. The II4-I42.5mm class represents legal-sized individuals. No clams were found smaller than 28.5mm. The red line indicates the lowest low tide mark for Rincon Beach, the break between intertidal and subtidal regions $(44.5 \mathrm{~m})$. This data does not reflect an adjustment for double the sampling effort in the subtidal. 